\title{
Geothermal Reservoirs - A Brief Review
}

\author{
Sayantan Ganguly and M. S. Mohan Kumar \\ Department of Civil Engineering, Indian Institute of Science, Bangalore - 560012 \\ Email: sayantan@civil.iisc.ernet.in; msmk@civil.iisc.ernet.in
}

\begin{abstract}
A brief discussion and review of the geothermal reservoir systems, geothermal energy and modeling and simulation of the geothermal reservoirs has been presented here. Different types of geothermal reservoirs and their governing equations have been discussed first. The conceptual and numerical modeling along with the representation of flow though fractured media, some issues related to non isothermal flow through fractured media, the efficiency of the geothermal reservoir, structure of the numerical models, boundary conditions and calibration procedures have been illustrated. A brief picture of the Indian scenario and some barriers related with geothermal power are discussed and presented thereafter. Finally some gaps of the existing knowledge and recent focuses of research are discussed.
\end{abstract}

Keywords: Geothermal reservoirs, Modeling and simulation, Conceptual model, Calibration, Boundary conditions.

\section{INTRODUCTION}

Geothermal energy is the energy naturally present inside the earth crust. When a large volume of hot water and steam is trapped in subsurface porous and permeable rock structure and a convective circulating current is set up, it forms a geothermal reservoir. Hochstein (1990) described a geothermal system as 'convective water in the upper crust of Earth, which, in a confined space, transfers heat from a heat source to a heat sink, usually the free surface'. A geothermal system is made up of three main elements: a heat source, a reservoir and a fluid, which is the carrier that transfers the heat (Dickson and Fanelli, 1994). A schematic view of a typical geothermal reservoir system with power

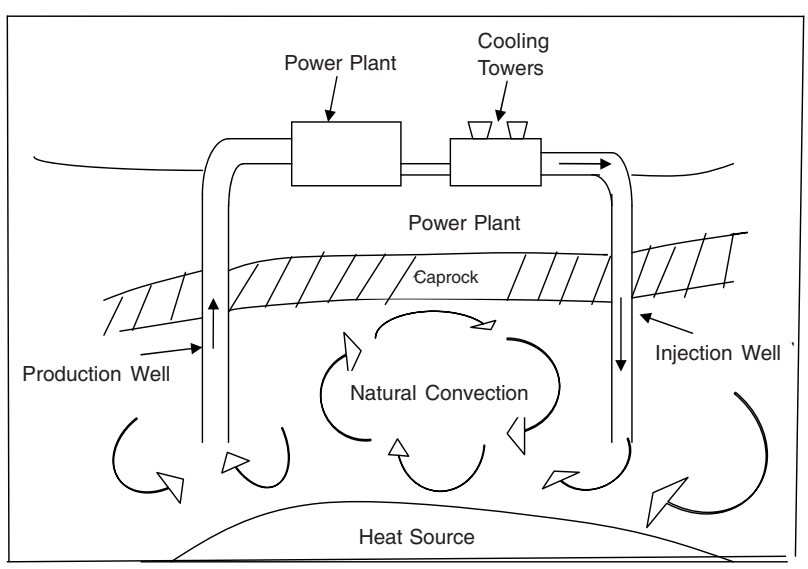

Fig.1. Schematic representation of a geothermal reservoir system with production and injection wells installed. plants and production and injection wells installed is shown Fig. 1.

As an alternative source of energy geothermal energy has been under attention of the researchers for quite some time. The reason behind this is the existence of several benefits like clean and renewable source of energy which has considerable environmental advantage, with no chemical pollutants or wastes are generated due to geothermal emissions, and the reliability of the power resource. Hence research has been directed in several directions like exploration of geothermal resources, modeling the characteristics of different types of geothermal reservoirs and technologies to extract energy from them. The target of these models has been the prediction of the production of the hot water and steam and thus the estimation of the electricity generating potential of a geothermal reservoir in future years.

\section{DIFFERENT GEOTHERMAL SYSTEMS}

The geothermal systems can broadly be classified into three systems hydrothermal, geopressured and hot dry rock systems (Faust and Mercer, 1979). When heat from a near surface source is transferred to porous media and the porous fluid within that by conductive and convective processes the system is called a hydrothermal one. The hydrothermal systems can be further categorized into liquid dominated and vapor dominated (or dry steam) systems (White et al. 1971) depending upon whether water or vapor is present as 
the continuous and pressure controlling phase. In vapor dominated systems water and vapor coexist together.

Geopressured systems on the other hand is a type of static system in which water gets trapped inside permeable sedimentary rock within low permeable rock strata. Trapped water is subjected to high pressure and temperature.

Finally the hot dry rock system is an artificial reservoir system in which boreholes are drilled and water is injected into hot igneous rock which is heated by similar process as the hydrothermal system. The injected water extracts heat from the rock body moving through the fractures and the hot water and steam is extracted by another borehole.

Geothermal systems are further classified depending on reservoir equilibrium state a static and dynamic systems. Dynamic systems as the name suggests consists of recharge and discharge of water in a continuous manner. The convective or circulating movement of water through the system is responsible for the heat transfer. Static systems on the other hand have minimum or no recharge and heat is transferred in the system mainly by process of conduction.

\section{GOVERNING EQUATIONS OF GEOTHERMAL RESERVOIRS}

Geothermal reservoir simulation needs a correctly constructed mathematical model to obtain a proper numerical solution of the system. A mathematical model for a geothermal reservoir needs to have information or understanding of -

1. Physical and chemical processes operating in the reservoir.

2. The initial conditions throughout the system and boundary conditions at the boundaries.

3. Hydrogeologic parameters (porosity, permeability etc) with their spatial variations.

4. Fluid properties (density, viscosity, enthalpy vapor pressure etc).

5. The locations of sinks and sources and their flow rates.

The flow of fluid inside a geothermal reservoir is a complex phenomenon. The flow can be characterized both as a single phase (water) multi-component (mainly liquid water and steam, with dissolved carbon-dioxide and $\mathrm{NaCl}$ ) flow or a multiphase flow consisting of two phases water (liquid phase) and steam (gaseous phase). Governing equations describing the phenomenon are developed in terms of conservation equations or balance laws of mass momentum and energy. Derivations and presentations of the mathematical models of geothermal reservoirs have been done by Mercer et al. (1974), Faust and Mercer (1977a),
Brownell et al.(1977), Witherspoon et al. (1975). The conservation equations should be considered for each phase in geothermal system. Constitutive relations are then used to simplify and reduce the number of equations. Different sets of variables can be used in formulating the governing equations of geothermal reservoir. Pressure-temperaturesaturation -pressure enthalpy, density-internal energy can be cited as examples. The governing equations in the form of partial differential equations are given below.

\section{Mass Balance}

Mass conservation equations are given for two phases water $(w)$ the wetting phase and steam $(s)$ the non-wetting phase, normally present in geothermal systems.

$$
\begin{aligned}
& \text { Steam: } \quad \frac{\partial\left(\phi S_{s} \rho_{s}\right)}{\partial t}+\nabla \cdot\left(\rho_{s} \vec{v}_{s}\right)-q_{s}-\dot{m}=0 \\
& \text { Water: } \quad \frac{\partial\left(\phi S_{w} \rho_{w}\right)}{\partial t}+\nabla \cdot\left(\rho_{w} \vec{v}_{w}\right)-q_{w}+\dot{m}=0
\end{aligned}
$$

Here $\phi$ represents the porosity, $S$ is the saturation, $\rho$ is the density, $q$ is the source term, $v$ is the averaged phase velocity and $m$ represents the mass transfer rate from liquid to vapor.

\section{Momentum Balance}

Momentum conservation equations are generally given in form of Newton's second law. Here Darcy's Law extended for multiphase flow through porous media is used. It should be noted that applicability of Darcy law is limited to a system of fractures. It is not valid to describe flow through a single fracture (Arbogast, 1989). In a geothermal reservoir medium, which consists of a system of fractures Darcy law can be applied as a momentum or dynamic equation for fluid flow analysis. The equations are given by

$$
\begin{aligned}
& \vec{v}_{s}=-\frac{\mathbf{K} k_{r s}}{\mu_{s}}\left(\nabla p_{s}-\rho_{s} g \nabla D\right) \\
& \vec{v}_{w}=-\frac{\mathbf{K} k_{r w}}{\mu_{w}}\left(\nabla p_{w}-\rho_{w} g \nabla D\right)
\end{aligned}
$$

Where $\mathrm{K}$ is the intrinsic permeability tensor, $k_{r}$ is the relative permeability, $D$ is the depth and $p$ is the phase pressure and $g$ is the gravitational constant.

\section{Energy Balance}

Energy balance equations are presented in terms of pressure an enthalpy as primary variables. Assumptions of 
zero capillary pressure and local thermal equilibrium are applied here.

$\frac{\partial}{\partial t}\left[\phi \rho h^{\prime}+(1-\phi) \rho_{r} h_{r}{ }^{\prime}\right]-\nabla \cdot\left[\frac{\mathbf{K} k_{r s} \rho_{s} h_{s}{ }^{\prime}}{\mu_{s}}\left(\nabla p-\rho_{s} g \nabla D\right)\right]-$ $\nabla \cdot\left[\frac{\mathbf{K} k_{r w} \rho_{w} h_{w}^{\prime}}{\mu_{w}}\left(\nabla p-\rho_{w} g \nabla D\right)\right]-\nabla \cdot\left[K_{m}\left(\frac{\partial T}{\partial p}\right)_{h} \nabla p\right.$

$\left.+K_{m}\left(\frac{\partial T}{\partial h^{\prime}}\right)_{p} \nabla h^{\prime}\right]-q_{h}=0$

where $\rho$ is the density of the total steam-water mixture, given by

$$
\rho=S_{w} \rho_{w}+S_{s} \rho_{s}
$$

with the sum of the individual phase saturation equals to 1 .

$$
S_{w}+S_{s}=1
$$

$h_{w}^{\prime}, h_{s}^{\prime}$ and $h_{r}^{\prime}$ are the enthalpies of water, steam and rock respectively and $h^{\prime}$ is the enthalpy of water steam mixture and is given by

$$
h^{\prime}=\frac{S_{s} \rho_{s} h_{s}^{\prime}+S_{w} \rho_{w} h_{w}^{\prime}}{\rho}
$$

$T$ represents the temperature and $q_{h}$ is the source/sink term.

The geothermal reservoir simulation problem is a complex multiphase multicomponent flow problem consisting of water in two phases (liquid and steam). The governing equations of multiphase flow are strongly coupled by the relative permeabilities and constraints given by Eqn. 7 and 9. The main numerical complexity of the governing equations of geothermal reservoirs arises due to the dependence of the capillary pressure $\left(p_{c}\right)$ and relative permeabilities of the phases $\left(k_{r}\right)$ on saturation. The relationships which define this dependence are called constitutive relations which are needed to describe the system completely. The capillary pressure can be expressed as

$$
p_{c}=p_{s}-p_{w}
$$

where $p_{s}$ is the non-wetting phase pressure of steam and $p w$ is the wetting phase pressure of water. The most widely used constitutive relationships between capillary pressure and saturation and that between relative permeability and saturations were parameterized by Brooks and Corey (1964) and van Genutchen (1980). The Brooks and Corey (1964) $p_{c}-S_{w}, k_{r}-S_{w}$ relations are given by

$$
\begin{aligned}
& p_{c}=p_{d} S_{e}^{-\frac{1}{\lambda}} \\
& k_{r w}=S_{e}^{\frac{2+3 \lambda}{\lambda}}
\end{aligned}
$$

$$
k_{m w}=\left(1-S_{e}\right)^{2}\left(1-S_{e}^{\frac{2+\lambda}{\lambda}}\right)
$$

where $p_{d}$ is the entry pressure or the displacement pressure for the fracture media, $\lambda$ is the pore size distribution index, $S_{e}$ is the effective saturation of the wetting fluid and is given by

$$
S_{e}=\frac{S_{w}-S_{r w}}{1-S_{r w}-S_{r n w}}
$$

where $S_{r w}$ and $S_{r n w}$ are the residual saturations for the wetting (water) and the non wetting(steam) phase. $k_{r w}$ and $k_{r n w}$ are the relative permeabilities of the wetting and nonwetting phase.

\section{CONCEPTUAL MODEL OF A GEORTHERMAL RESERVOIR SYSTEM}

"A good understanding of the important aspects of the structure of the system and the most significant (physical and chemical) aspects in it is referred to as its conceptual model" (O'Sullivan et al. 2001). Generally it consists of few sketches of several horizontal and vertical sections of the system containing information about geological structure, temperature, geochemistry, resistivity and surface activity, important features of a geothermal system like surface manifestations (i.e. hot springs, steaming grounds, etc), flow boundaries, main geologic features such as faults and layers, zones of high and low permeability, iso- therms, location of deep inflows and boiling zones, geophysical data (resistivity boundaries, heat flow contours), etc (O'Sullivan et al. 2001). A huge amount of geological, geophysical, geochemical data is required in setting up a conceptual model.

\section{Flow through Fractured Media}

Most of the geothermal reservoirs all over the world are situated in fractured rock media where the main flow occurs through a network of interconnected fractures. Conceptualizing the fluid flow and heat transfer mechanisms through a fractured media requires either a gross simplifications it or detailed description of the aquifer properties controlling the flow. A fractured media consists of primary rock porosity along with secondary porosity created by cracks, fractures, joints and shear zones which form an interconnected network for flow and transport. Hence analyzing flow and transport through a fractured media requires knowledge of the permeability of the rock matrix as well as permeability created by the network of fractures. The rock matrix although having very low 
permeability, can contribute to the flow locally. Different approaches are followed to simulate the flow through fractures depending on the physical characteristics of the reservoir (fracture spacing and connectivity, permeability of rock matrix etc) (Pruess, 2002).

The Effective Continuum Method or ECM is the simplest among all of the approaches in which the fractured media is represented as a single porous media with properties chosen in such a way so as to represent approximately the original fractured media.

Explicit modeling of a fracture may be another approach which is applicable to idealized cases of a major fracture or fault zone whereas in real scenarios due to presence of numerous fractures in a domain explicit representation is not viable.

A third approach to model flow through fractured media and the most widely used one now a days is the double porosity method proposed by Barenblatt et al. (1960) and Warren and Root (1963). This approach considers the interconnected fracture zone permeability and rock matrix permeability separately. The main advective flow is considered to be through the fracture network only due to low permeability of the rock matrix. The matrix and fractures interact locally by exchange of fluid by means of cross flow or interporosity flow which is governed by the local difference in pressure or temperature between the two media. The concept is represented by a cube model of fractured reservoir shown in Fig.2. Gerke and Genuchten (1993) proposed a dual porosity mathematical model for one dimensional vertical flow through variably saturated porous media

$$
\begin{gathered}
C_{f} \frac{\partial h_{f}}{\partial t}=\frac{\partial}{\partial z}\left(K_{f} \frac{\partial h_{f}}{\partial z}-K_{f}\right)-\frac{\Gamma_{w}}{w_{f}} \\
C_{m} \frac{\partial h_{m}}{\partial t}=\frac{\partial}{\partial z}\left(K_{m} \frac{\partial h_{m}}{\partial z}-K_{m}\right)+\frac{\Gamma_{w}}{1-w_{f}}
\end{gathered}
$$

Subscripts $f$ and $m$ are used for flow through fracture and matrix respectively, $h$ represents the pressure head, $C=d \theta / d h$ is the specific water capacity where $\theta$ is the water content, $K$ the hydraulic conductivity, $w_{f}$ is fractional pore volume w.r.t the total rock volume, $z$ is vertical direction taken downward positive and $\Gamma_{\mathrm{w}}$ represents the mass transfer term between facture and matrix medium.

The mass transfer term between the fracture and matrix here is a critical term to model in all dual porosity/ permeability models. In several studies (Philip, 1968; Simu ${ }^{\circ}$ nek et al. 2001) the transfer term is assumed to be proportional to the difference of effective water contents of two regions given by

$$
\Gamma_{w}=\frac{\partial \theta_{m}}{\partial t}=\omega\left[S_{e}^{f}-S_{e}^{m}\right]
$$

where $\Gamma_{w}$ is the mass transfer rate between fracture and matrix, $\theta_{m}$ represents the water content of the matrix, $\omega$ is a first order rate coefficient and $S_{e}^{f}$ and $S_{e}^{m}$ are effective fluid saturations of the fracture and matrix zone respectively. Compared to this approach to model the mass transfer term the pressure head based approach (Gerke and van Genuchten, 1993b) given below which considers $\Gamma_{w}$ to be proportional to the difference in the pressure heads between the fracture and matrix regions is more realistic since it considers the pressure gradient as the driving force (like Darcy law) for the fracture-matrix mass transfer and hence considers the interface velocity between fracture and matrix zone

$$
\Gamma_{w}=\alpha_{w}\left(h_{f}-h_{m}\right)
$$

where $h_{f}$ and $h_{m}$ are the pressure heads for fracture and matrix regions $\alpha_{w}$ is a first order rate coefficient given by

$$
\alpha_{w}=\frac{\beta}{d^{2}} K_{a} \gamma_{w}
$$

where $\beta$ is a dimensionless geometry coefficient, $d$ is the characteristic half width of the matrix block, $K_{a}$ represents the effective hydraulic conductivity of the matrix at the fracture matrix interface and $\gamma_{w}$ is a dimensionless scaling factor. One thing should be noted that here $h_{f}$ and $h_{m}$ are average pressure heads for fracture and matrix respectively and spatial and temporal variation of them (which is the actual case) are not considered here.

Double porosity concept assumes the interporosity flow to be quasi steady and governed by local difference in pressures between fractures and matrix which is applicable

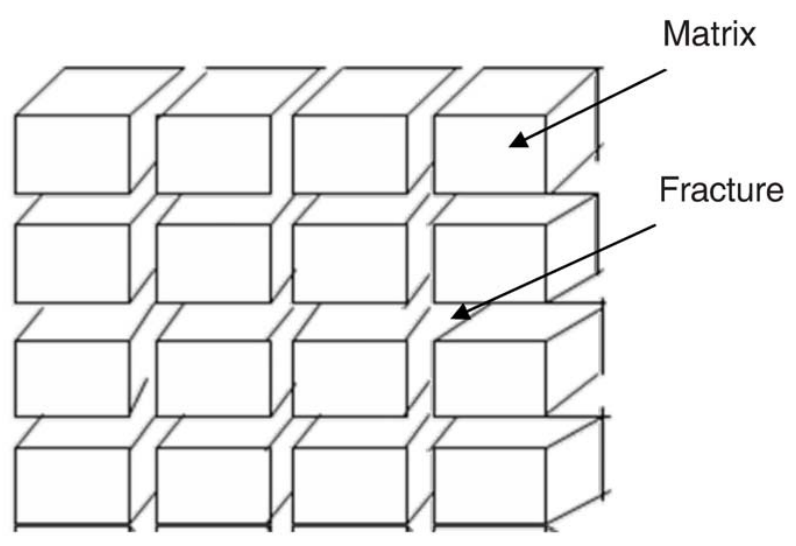

Fig 2. Idealized cube model of matrix fracture system in Double Porosity model. 
only for single phase isothermal flows with fluids of small compressibility and not for non-isothermal, multiphase flow scenarios like that of geothermal reservoirs. Hence an extension was made to the double porosity model by Pruess and Narasimhan $(1982,1985)$ named 'Multiple Interacting Continua' or MINC. The model treats interporosity flow in a fully transient way and the gradients of pressure, temperature and mass fraction gradients are defined at the fracture matrix interface. Matrix blocks are discretized into volume elements which subgrids the matrix blocks into separate continuums as shown in Fig 3. The interporosity flow is assumed to be one dimensional towards the fractures or away from it.

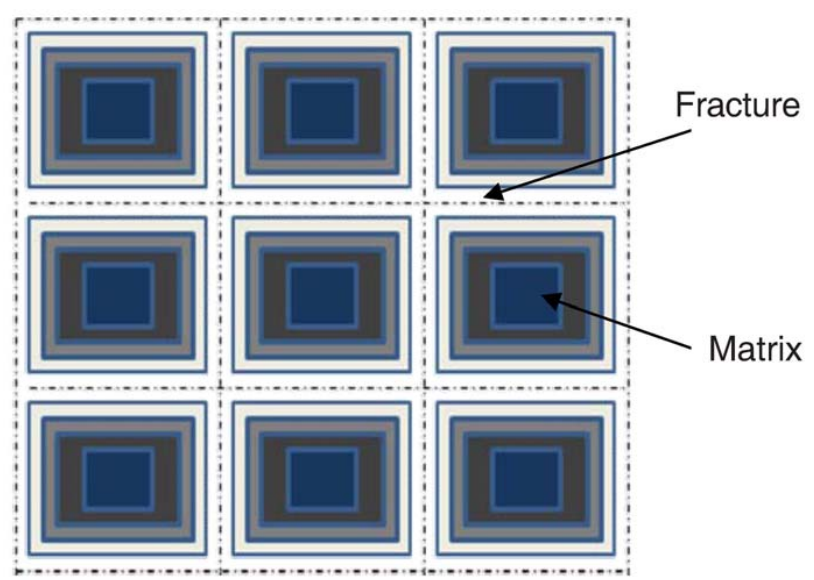

Fig 3. Discretization of matrix and fracture into different volume elements in MINC method.

The mathematical models describing the fluid flow and heat transport through the fractured network are all based on the continuum theory and correspond to a representative elementary volume ( $R E V)$. Mathematical models can be broadly classified into three categories depending on the various scales to analyze the fluid flow and heat transport mechanisms. They are (1) Discrete Fracture Network (DFN) (2) Stochastic Continuum (SC) and (3) Channel Network model $(C N)$ (Dershowitz et al. 1999; Selroos et al. 2002; Gylling et al. 2004).

The discrete fracture model as the name suggests considers flow through individual fractures which are considered to be interconnected. A statistical description of the fracture geometry and hydraulic properties such as location, size, orientation, spatial structure is needed to set up a DFN model. The advantage of DFN is that it incorporates the description of the fracture or fracture zones explicitly. The disadvantage on the other hand is collecting and handling a huge amount of data which sometimes may be too difficult to collect also.
The stochastic continuum approach on the other hand considers the fractured media can be described on the basis of some spatially variable spatial parameters which vary according to some random functions. The domain of modeling is discretized to cells and based on the random functions some random values of the properties are assigned. Finite volume or finite difference models are then applied to calculate the average properties.

The Channel network model conceptualizes the flow within the fractured media to occur through certain discrete channels which intersect at various intervals. The characteristics of the fractured network are neglected here and so the amount of data required are lesser than DFN although this method considers the discrete nature of the pathways. Consideration of flow through discrete channels allows the use of one dimensional element to discretize the domain which reduces the computational difficulty.

Fluid flow through a fracture can be fully described by the Navier-Stokes equation. However as the groundwater flow velocity and the Reynolds number associated with it is small, the advective terms can be considered to be negligible. Based on the above assumptions and considering the velocity to be depth averaged over the aperture the fluid flow equations is given as (Muralidhar, 1990)

$$
\begin{gathered}
\frac{\partial \bar{u}}{\partial t}-\frac{1}{R_{e}}\left(\frac{\partial^{2} \bar{u}}{\partial x^{2}}+\frac{\partial^{2} \bar{u}}{\partial y^{2}}-\bar{u} \int_{0}^{h} f(z) d z\right)=-p_{x} \\
\frac{\partial \bar{v}}{\partial t}-\frac{1}{R_{e}}\left(\frac{\partial^{2} \bar{v}}{\partial x^{2}}+\frac{\partial^{2} \bar{v}}{\partial y^{2}}-\bar{v} \int_{0}^{h} f(z) d z\right)=-p_{y} \\
\frac{\partial \bar{u}}{\partial x}+\frac{\partial \bar{v}}{\partial y}=0
\end{gathered}
$$

where $\bar{u}$ and $\bar{v}$ are the depth averaged velocities in $x$ and $y$ directions respectively, $p_{x}$ and $p_{y}$ are the depth averaged pressures in $x$ and $y$ directions respectively, $t$ is time, $f(z)$ is the function describing the variation of $u$ and $v$ over the depth, $R_{e}=\left(u_{m} d / v\right)$ is the Reynolds number where $u_{m}$ is the mean velocity in the fracture, $d=$ characteristic length of the fracture and $v$ is the kinematic viscosity of the fluid.

Assuming the temperature to be uniform over the depth the depth averaged advection-diffusion equation is given as

$$
\frac{\partial T}{\partial t}+\bar{u} \cdot \nabla T=\frac{1}{P_{e}}\left(\frac{\partial^{2} T}{\partial x^{2}}+\frac{\partial^{2} T}{\partial y^{2}}\right)
$$

where $T$ is temperature, $P_{e}=\left(u_{m} d / \alpha\right)$ is Peclet number where $\alpha$ is the thermal diffusivity of the fluid. 


\section{Some Issues Regarding Non Isothermal Flow through Fractured Media}

Since the fractured media is originally a fully coupled medium, coupled interaction exists between the matrix and fracture in terms of fluid diffusion, heat transfer and rock deformation. Considering the fracture to be a vertical plane of uniform width (Fig. 4) the heat balance equations (Ghassemi et al. 2008) for a fracture segment and matrix are given respectively by

$$
\frac{\partial T(x, 0, t)}{\partial t}+v(x, t) \frac{\partial T(x, 0, t)}{\partial x}-D_{L} \frac{\partial^{2} T(x, 0, t)}{\partial x^{2}}=\left.\frac{2 K_{r}}{\rho_{f} c_{f} e(x, t)} \frac{\partial T(x, y, t)}{\partial y}\right|_{y=0}
$$

and

$$
\frac{K_{r}}{\rho_{r} c_{r}} \frac{\partial^{2} T(x, y, t)}{\partial y^{2}}=\frac{\partial T(x, y, t)}{\partial t}+q_{L}(x, t) \frac{\partial T(x, y, t)}{\partial y}
$$

here $T$ is temperature, $v$ is the velocity of fluid in the fracture, $D_{L}$ represents the thermal dispersion coefficient, $K_{r}$ represents the rock thermal conductivity, $e$ is the fracture aperture, $c_{f}$ and $c_{r}$ are the specific heat of the fluid and rock respectively and $\rho_{f}$ and $\rho_{r}$ is the density of the fluid and rock respectively.

The geothermal reservoir being a deformable porous fractured medium due to the extraction of the geothermal fluid it undergoes deformation due to the thermal stress produced. The apertures of the fractures undergo changes and hence the fracture permeability is also evolutes accordingly. Ghassemi and Suresh Kumar (2007) derived an analytical solution which is given below for the change in aperture fracture with time resulting from thermoelastic deformation assuming the thermally induced stress is one dimensional and rock deformation occurs only by normal strain.

$$
\frac{\partial e(x, t)}{\partial t}=\frac{2(1+v) \alpha_{T} \lambda_{m}}{(1+v) \rho_{m} C_{m}}\left(\frac{2 \Delta T A_{2}}{\sqrt{\pi}} \exp \left[-\left(A_{1}\right)^{2}\right]\right)
$$

where $v$ is the Poisson's Ratio, $\alpha_{T}$ represents the linear thermal expansion coefficient, $\rho_{m}$ represents the density of the matrix, $\lambda_{m}$ represents the thermal conductivity of the matrix, $C_{m}$ represents the rock specific heat, $\Delta T=T(x, y, t)-T_{\infty}$, where $T_{\infty}$ is the temperature at infinity,

$$
A_{1}=\frac{x \sqrt{\lambda_{m} \rho_{m} C_{m}}}{Q \rho_{m} C_{w} \sqrt{t}} \text { and } A_{2}=\frac{\sqrt{\rho_{m} C_{m}}}{2 \sqrt{\lambda_{m} t}}
$$

where $Q$ is the volumetric injection rate.

Results of the research work showed that the thermal stresses consequences in the reduction of the aperture along the length of fracture which is maximum near the injection

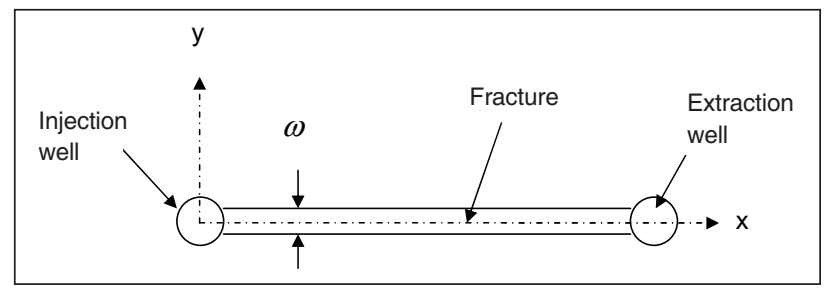

Fig.4. Top view of an idealized vertical fracture extending from injection to production/extraction well.

well. The fracture permeability $\left(K_{f}\right)$ calculated from the 'cubic law' $K_{f}=e^{2} / 12$, reduces accordingly and the volume of flow and pressure distribution undergo significant change due to small change of the aperture induced by thermal stress generating from heat extraction.

Modeling of reactive transport under non-isothermal conditions as in the case of a geothermal reservoir has been an important aspect since the solute transport results in changing the fracture aperture which in turn affects fracture permeability. Phenomenon like quartz dissolution or precipitation, nonlinear sorption of the solutes thus has a contribution in maintaining the reservoir efficiency. Suresh Kumar and Ghassemi (2005) have presented a numerical model to simulate combined effect of the thermal and reactive solute transport in a coupled fracture-matrix system using dual porosity concept. Results from their model show that higher the initial temperature of the rock higher is the quartz dissolution near the injection well which increases the fracture aperture. It is also inferred that higher initial velocity of flow in the fracture, higher initial fracture aperture, lower reservoir porosity, lower effective matrix diffusion coefficient and lower reservoir thermal conductivity results in higher dissolution of quartz and thus reducing the resistance of flow between the injection and production well.

Non linear sorption on the other hand is another phenomenon to retard the solute movement in the fracture affecting the extent of solute spreading in the fracture. Natarajan and Suresh Kumar (2010) studied the effect of non linear sorption on solute transport in a coupled sinusoidal facture-matrix system. Results suggest that as sorption intensity reduces sorption becomes more favorable and the concentration of solutes along the fracture reduces. Sorption intensity has also negligible effect with respect to the change of fracture aperture.

The flow rate the within the fracture is dependent on a lot of factors. Fluid flow within a fracture is essentially a coupled process between fluid flow and rock deformation (Wu and Pruess, 2000) since geothermal reservoir medium is a deformable fractured medium. Fluid density, porosity and permeability are all functions of the pressure which is 
responsible in controlling the flow rate. Pressure changes induced by the deformation of the fracture walls results in density change of the reservoir fluid which in turn influences the flow rate. According to Indraratna et al. (2003) flow rates of the phases of a two phase flow (air and water) may decrease by $80 \%$ when the confining pressure exceeds 5 $\mathrm{MPa}$. Temperature changes as in the case of non isothermal flows also plays vital role. Other effects like thermo and poroelasticity, reactive transport of solutes (precipitation/ dissolution, non-linear sorption) also results in change of fracture aperture controlling the fracture permeability which governs the flow rate. Hence a constant flow though the fractures is essentially a simplified assumption and practically not feasible to maintain.

Another issue regarding the non-isothermal flow through the fractured reservoir is the variation of pressure in the reservoir due to injection and production. The method of injecting fluid into the geothermal reservoir is necessary to maintain the pressure inside the reservoir. Additionally it reduces amount of non-condensable gases (NCG) and benefits the energy extraction. The injected water is heated up by heat transfer from the rocks and starts to vaporize. Due to the vaporization the volume of the fluid expands and pressure increases which propagate away from the injection plume. Pruess (2008) found that due to the injection, the pressure is highest near the injection well (where temperature is minimum due to cold water injection) and then there is a sharp gradient of pressure followed by gradual decrement towards the production well. With continuous injection the pressure near the injection well also increases with time. But with passage of time the pressure away from the injection well decreases due to the overall heat transfer from the rock to the injected water.

\section{GEOTHERMAL RESERVOIR EFFICIENCY}

A big concern regarding the geothermal reservoir is to maintain its efficiency. The lifetime efficiency of a geothermal reservoir can be defined as the ratio of the heat produced over its lifetime to the total available heat content of the reservoir (Brown et al. 1999). The efficiency of the geothermal reservoir system is dependent greatly on the fracture aperture thickness. The production or extraction from the reservoir depends directly on the permeability of the fractured media of the reservoir. The permeability in turn is dependent on the square of the fracture aperture thickness as calculated from the 'cubic law'. Hence changes in fracture aperture would affect the reservoir efficiency a lot.
Thermo and poroelasticity plays vital role in determining the reservoir efficiency as these two effects are hugely responsible for changing the aperture of the fractured media. In general the geothermal reservoir is a fully coupled thermoporoelastic medium. Ghassemi et al. (2008) have shown that these two effects play an opposite role to change the fracture aperture. Thermally induced stresses tend to increase the fracture aperture whereas poroelastic effects are responsible for closure of fracture opening along the length of fracture, both the effects being maximum at near the injection point and gradually reducing towards the outlet. The thermoelastic effects being predominant the combined effect of the two with fluid losses from the fracture increases the fracture opening with time which reduces the pressure in the fracture with time due to increase of fracture aperture and hence less injection pressure would be needed at the inlet.

Efficiency also depends on some other factors like the depth of the production and injection wells as evidently at more depth the wells will be exposed to more temperature leading to more heat extraction. Spacing of the injection and production wells also plays vital role in reservoir efficiency. Injection of water is essential in addition to fluid extraction from the reservoir in order to maintain the reservoir pressure and to stimulate the flow from injection to production wells. Close spacing of the injection and production wells helps in maintaining the reservoir pressure. But since the injected fluid is much colder than the reservoir fluid it results in reduction of the temperature near the injection well. As this temperature front of colder fluid grows with time and reaches at the production well, the temperature there remains no longer constant and the reservoir efficiency may be affected (Stopa and Wojnarowski, 2006) Hence sufficient spacing of the injection and production wells is necessary to maintain constant temperature at the production well. The reservoir efficiency is therefore dependent on two contrasting situation of increase in reservoir pressure by decreasing distance between the wells and increasing the distance concerning the reservoir temperature reduction (Kocabas, 2005).

To maintain the efficiency of a geothermal reservoir the connectivity between the injection between the injection and the production wells has to be ensured. Hydraulic stimulation has been a mean of ensuring that. Higher injection pressure is applied in this method which results in higher mean pressure of the reservoir which causes access of the reservoir fluid to more rock volume and reduction of flow impedance between injection and production wells in enhanced geothermal systems (EGS) (Brown et al. 1999). However increase of injection pressure has resulted in few cases in 
short circuiting of flow paths and water losses from the reservoir e.g. in Hijiori reservoir, Japan (Tenma et al. 1997) and Rosemanowes reservoir, United Kingdom (Richards et al. 1994). Another problem regarding hydraulic stimulation is that the injection of excessive cold water may reduce the temperature of the surrounding hot rock and the method of fracturing may cause microscale earthquakes too. Hence the feasibility of the hydraulic stimulation has been limited by these issues.

\section{MODELING AND SIMULATION}

Like other fields of modeling and simulation geothermal systems can also be modeled in deterministic as well as stochastic way. Models of geothermal reservoir systems can be broadly classified into (1) natural state models or free convection models which are the models of the systems without exploitation or prior it and (2) models to study the effects of exploitations from a geothermal reservoir. Geothermal reservoir models can be further classified into lumped parameter models and distributed parameter models. In lumped parameter models geothermal reservoir systems are considered as a single element. The variation of rock and fluid properties are neglected in space and hence the governing equations reduce to a set of ordinary differential equation with time as only independent variable or a set of equivalent algebraic equations representing total mass and energy (Witherspoon et al. 1975). A lumped parameter model is the simplest way of describing the reservoir phenomenon. Application of this approach is done by Whiting and Ramey (1969), Cady (1969), Brigham and Morrow (1974), Martin (1975), Sarak et al. (2003), Tureyan et al. (2009) to name a few.

Distributed parameter models on the other hand consider spatial variation of the rock and fluid in reservoir systems. The governing equations are complex here and hence can't be solved using simple analytical techniques. Numerical modeling is required for this purpose. With the advancement of the modern computers, it is now possible to solve complex non linear partial differential equations like those governing the flow in geothermal reservoirs. Thereafter a lot of research work has been done beginning in early 1970s (e.g. Cheng and Lau, 1973; Mercer and Pinder, 1973). Theoretical studies and numerical modeling and simulation of geothermal reservoirs have been performed by (Faust and Mercer, 1977a, b; Faust and Mercer 1979; Antunez et al. 1990a, b, 1991, 1994; Bodvarsson et al. 1990a, b, 1991; O’Sullivan et al. 1990, 1998; Sanyal et al. 1990; Williamson, 1990, 1992; Menzies et al. 1991; Pritchett et al. 1991; Battistelli et al. 1992, 1998a; Hanano, 1992a,b; Axelsson and Bjornsson, 1993; Pham and Menzies, 1993; Sakagawa et al. 1994, 2000; Hu, 1995; Menzies and Pham, 1995; Pritchett and Garg, 1995; M.J. O’Sullivan et al. (2001); Boardman et al. 1996; Kiryukhin, 1996; Antics, 1997, 1998, 2000; White et al. 1997; Butler et al. 2000; Sanyal, 2000; Sanyal et al. 2000; Todesco, 1995).

\section{Model Construction}

The geothermal reservoir models developed so far have a coarse grid size e.g. Faust and Mercer (1979) used a finite difference grid in simulating the Wairakei hydrothermal system, New Zealand which had 150 blocks covering an area of $74.5 \mathrm{~km}^{2}$. In general typical dimensions of 200$300 \mathrm{~m}$ minimum in Vertical and 100-200 m minimum in horizontal directions are used for all practical purposes. The main challenge remains in representing the fractured rock media by this coarse discretized geometry. Many of the researchers in this respect have used the porous media approach while the others have used double porosity or MINC (Atanuez et al. 1994; Menzies and Pham, 1995; Butler et al. 2000) or the explicit representation of fractures (Axelsson and Bjornsson, 1993; Boardman et al., 1996; Antics, 1998). The most widely used simulators or codes used for geothermal reservoir simulations are TETRAD (Vinsome and Shook, 1993), STAR (Pritchett, 1995) and TOUGH2 (Pruess, 1990b). All these simulators can handle three dimensional complex multiphase multi-component flows.

\section{Boundary Conditions}

Boundary conditions are an important aspect in setting up a geothermal reservoir model. Different types of boundary conditions are generally used by different modelers. Geothermal reservoirs generally represent a convective system of heat and mass and hence the deep upflow in the system is represented by suitable heat and mass source at the base. Generally boundaries of the domain are kept sufficiently away from the main reservoir zone such that the boundary condition does not have any considerable influence on the performance of the model.

No flow boundary conditions have been used by some of the modelers while others have applied constant temperature and pressure boundary conditions. Specifying flux at the boundary is another hydrodynamic boundary condition. Whereas constant temperature at boundary, no heat flow or specified heat fluxes are the thermodynamic boundary conditions used in geothermal reservoir simulation (Mercer and Faust, 1979). Another practice has been assigning mass injection or production rates at boundary blocks. Initial conditions in terms of thermo- 
dynamic variables at the starting of a simulation determine whether the reservoir is in liquid dominated or vapor dominated state whereas the boundary conditions determine the flow conditions in the reservoir (Mercer and Faust, 1979).

\section{Model Calibration}

Calibration can be defined here as a process of modifying the input parameters to a model until the output from the model matches an observed set of data. In case of geothermal reservoirs model calibration is performed in two steps (O’Sullivan, 1985; Bodvarsson et al., 1986b; Pruess, 1990a, Butler et al. 2005, Pham et al. 1993), the initial or natural state modeling followed by historical data matching. Whereas the first step is indispensible for the calibration purpose the second step can only be performed when some production history of the geothermal reservoir exists. In initial state, modeling inputs like rock properties, the permeability structure of the domain, the location and magnitude of upflow, enthalpy etc are adjusted by trial and error until a satisfactory match is found to the simulated data of temperature and pressure distribution, and surface outflows of heat and fluid with that of the observed data. The model has to be run for geological time scales (may be thousands of years) until a quasi-steady condition is reached when calculated and observed data match within a close tolerance. Then the model is assumed to be representative of the initial state of the reservoir (Butler et al. 2005) and is ready for the second step of calibration the historical data matching or history matching. The purpose of this step is matching the simulated data in response to production to that of the production history of the reservoir. First, the locations of production, injection and observation wells and their corresponding data are assigned to appropriate grid blocks. The pressure and temperature distribution are taken from natural state model and the simulation is run for the total production period (O'Sullivan et al. 2001). A wide variety of data should be matched in this step which includes reservoir temperature and pressure distribution, discharge enthalpy and temperature, salinity and gas content etc. Now a days with the modern advancements, automatic history matching is possible using inverse modeling techniques obtaining optimal parameters by computer (Finsterle and Pruess, 1995; White, 1995b; Finsterle et al., 1997) which saves the labor of manual adjustment of the input data (O'Sullivan et al. 2001). Once the model of a geothermal reservoir is calibrated by these two steps it can be used for forecasting the future production rates and the temperature, pressure and enthalpy distribution.

\section{SCENARIO IN INDIA}

India has got a capacity of producing a total of about $10600 \mathrm{MW}$ of geothermal power which is five times greater than the combined power being produced by all other non conventional energy sources like solar, wind or biomass (Chandrasekharam, 2000). But unfortunately it is yet to appear as a geothermal power producing country. The reason behind this is the huge availability of coal. With increasing environmental concern associated with the conventional energy sources a clean, renewable and reliable energy source like geothermal can be considered as a solution to cater the increasing demand of power in coming decades. The potential geothermal provinces in India and temperatures of their surface discharges, heat flows and geothermal gradients associated with them are enlisted in Table 1.

Table 1. Potential Geothermal provinces of India (Chandrasekharam, 2000)

\begin{tabular}{lcccc}
\hline Province & $\begin{array}{c}\text { Surface } \\
\text { Discharge } \\
\text { temperature } \\
\left({ }^{\circ} \mathrm{C}\right)\end{array}$ & $\begin{array}{c}\text { Reservoir } \\
\left({ }^{\circ} \mathrm{C}\right)\end{array}$ & $\begin{array}{c}\text { Heat Flow } \\
\left(\mathrm{mW} / \mathrm{m}^{2}\right)\end{array}$ & $\begin{array}{c}\text { Thermal } \\
\text { gradient } \\
\left({ }^{\circ} \mathrm{C} / \mathrm{km}\right)\end{array}$ \\
\hline Himalaya & $>90$ & 260 & 468 & 100 \\
Cambay & $40-90$ & $150-175$ & $80-93$ & 70 \\
West coast & $46-72$ & $102-137$ & $75-129$ & $47-59$ \\
SONATA & $60-95$ & $105-217$ & $120-290$ & $60-90$ \\
Godavari & $50-60$ & $175-215$ & $93-104$ & 60 \\
\hline
\end{tabular}

On the basis of enthalpy and temperature characteristics the geothermal provinces in India can be classified broadly into two categories medium enthalpy systems $\left(100^{\circ} \mathrm{C}-200^{\circ} \mathrm{C}\right)$ and low enthalpy systems $\left(<100^{\circ} \mathrm{C}\right)$ (Razdan et al. 2008). The medium enthalpy zones are associated with younger intrusive granite zones (Himalaya), zones with major tectonic features (West coast of Maharashtra, Satpura, Tattapani in Chhattisgarh etc), rift and graben zones (Damodar, Godavari and Mahanadi basins) and Quaternary and tertiary sediment zones (Cambay basin in west coast). Low enthalpy zones are generally tectonically less or non active zones. Peninsular India although composed mainly of hard rocks the region is tectonically non active and associated with tertiary tectonism hence is devoid of any geothermal belt.

\section{SOME BARRIERS}

The main problem in using geothermal energy is that the reservoirs are very site specific and the power plants must be located near it because the transport of steam and 
hot water over long distance is not possible. Secondly the exploration of geothermally active sites is very expensive and includes high risk. The drilling process itself accounts for one third to one half of the total geothermal project. The other energy sources like hydropower, wind or solar energy are better established which goes against the preference of geothermal power against others.

\section{CONCLUDING REMARKS}

In the present work some aspects related with geothermal energy and geothermal reservoir modeling has been presented. Evidently geothermal reservoir simulation is one of the hot topics of research as the demand for ecofriendly energy resources is increasing. Construction of large three dimensional models has been possible with the advanced computer facilities. Research endeavors further extend to make the models more accurate and reduce the uncertainties better understanding of the coupled processes. Non isothermal multiphase flow modeling like that geothermal reservoir flow has governed the modeling procedures in other fields like the nuclear waste disposal, vadose zone hydrology, thermally enhanced oil recovery and Aquifer Storage, Transport and Recovery (ASTR) etc. Still there are some gaps in knowledge regarding the geothermal reservoir phenomenon which are still to be filled up and on which the research activities are focusing now-a-days are:

1. Better representations of the rock fluid interaction by hydrothermal mechanical coupling (Kohl et al. 1995a, b; Noorishad and Tsang, 1996; Bower and Zyvoloski, 1997) or coupling between geothermal fluid flow and rock stresses which is necessary in enhanced geothermal systems (EGS) and hot dry rock (HDR) geothermal reservoirs.

2. Improved description of the reservoir fluid which was previously considered as pure water. Recent trends are to include carbon dioxide as dissolved gas (Zyvoloski and O'Sullivan, 1980, Pritchett et al. 1981; O'Sullivan et al. 1985), dissolved solids such as $\mathrm{NaCl}$ (Burnell, 1992; Battistelli et al. 1997).

3. Chemical interactions of rock matrix fluid and that of different dissolved and gaseous components.

4. Automatic history matching or model calibration techniques by use of computer by inverse modeling techniques (White, 1995b; Finsterle et al. 1997; Finsterle and Pruess, 1999) removes the tedium manual trial and error model adjustments.

5. Handling the fluid properties at near critical or supercritical temperatures, which is necessary to simulate the deep zone in geothermal formations. (Hanano and Seth, 1995; Kissling, 1995; Hayba and Ingebritsen, 1997; Palliser and McKibbin, 1998; Yano and Ishido, 1998).

6. Development of advanced and improved numerical solution techniques for efficient modeling of large reservoir systems (Moridis and Pruess, 1998), coupling between reservoir and wellbore flow (Murray and Gunn, 1993; Hadgu et al. 1995).

Beside power production, geothermal energy is also being used currently in injecting water inside aquifers storing warm water using geothermal heat and extracting in time of need. This process is called aquifer storage and recovery or ASR. In spite of the advanced modeling and simulation work that is being carried out, it should be remembered that the introduction of the field experiments for geothermal reservoir operation and maintenance are still indispensible.

\section{References}

Antics, M.A. (1997) Computer simulation of the Oradea geothermal reservoir. Proceedings of the $22^{\text {nd }}$ Workshop on Geothermal Reservoir Engineering, Stanford University, Stanford, California, 27-29 January 1997, pp.491-495.

Antunez, E.U., Bodvarsson, G.S. and Walters, M.A. (1994) Numerical simulation study of the NorthwestGeysers geothermal field, a case study of the Coldwater Creek steamfield. Geothermics, v.23 (2), pp.127-141.

Antunez, E.U., Menzies, A.J. and Sanyal, S.K. (1991) Simulating a challenging water dominated geothermal system: the Cerro Prieto field, Baja California, Mexico. Proceedings 16th Workshop on Geothermal Reservoir Engineering, Stanford University, Stanford, CA, 23-25 January 1991, pp.183-191.

Antunez, E.U., Sanyal, S.K., Menzies, A.J., NaKa, T., Takeuchi, R., Iwata, S., SAeki, Y. and Inoue, T. (1990a) Forecasting well and reservoir behavior using numerical simulation, Uenotai geothermal field, Akita Prefecture, Japan. Trans. Geothermal Resources Council, v.14, pp.1255-1262.

Antunez, E.U., Sanyal, S.K., Carella, R. and Guidi, A. (1990b) Quantitative verification of the hydrogeological model of the Mofete geothermal field, Campania, Italy. Trans. Geothermal Resources Council, v.14, pp.1263-1270.

Arbogast, T. (1989) Analysis of the simulation of a single phase flow through a naturally fracture reservoir. SIAM Jour. Numer. Anal., v.26(1), pp.12-29.

Axelsson, G. and Buornsson, G. (1993) Detailed three-dimensional modeling of the Botn hydrothermal systemin N-Iceland. Proceedings of the 18th Workshop on Geothermal Reservoir Engineering, StanfordUniversity, Stanford, California, 26-28 January 1993, pp.159-166. 
Barenblatt, G.E., Zheltov, I.P. and Kochina, I.N. (1960) Basic Concepts in the Theory of Seepage of Homogeneous Liquids in Fissured Rocks. Jour. Appl. Math, v.24(5), pp.12861303.

Battistelli, A., Calore, C. and Pruess, K. (1997) The simulator TOUGH2/EWASG for modeling geothermal reservoirs with brines and non-condensible gas. Geothermics, v.26 (4), pp.437464.

Battistelli, A., Calore, C., Rossi, R. and Wu, F. (1992) Reservoir engineering study of Nagqu geothermal field (Tibet autonomous region, PRC). Presented at the High-Temperature Geothermal Resources Workshop, Lhasa, 9-16 August 1992.

Battistelli, A., Yiheyis, A., Calore, C., Ferragina, C. and Abatneh, W. (1998a) Tendaho geothermal project (Ethiopia): reservoir engineering studies in the Dubti area. Proceedings of the World Renewable Energy Congress V, Florence, 1998, pp.2741-2745.

Brigham, W.E. and Morrow, W.B. (1974) $P / Z$ behavior for geothermal steam reservoirs. Paper SPE 4899 presented at the 44th Annual California Regional Meeting of the Society of Petroleum Engineers, AIME, San Francisco, California.

Boardman, T.S., Ali Khan, M. and Antunez, E. (1996) TOUGH2/ PC application simulation project for Heber geothermal field, California, a progress report. Proceedings of the 21st Workshop on GeothermalReservoir Engineering, Stanford University, Stanford, California, 22-24 January 1996, pp.135-141.

Bodvarsson, G.S., Bjornsson, S., Gunnarsson, A., Gunnlaugsson, E., Sigurdsson, O., Stefansson, V. and Steingrimsson, B. (1990b) The Nesjavellir geothermal field, Iceland: 1. Field characteristics and development of a three-dimensional numerical model. Jour. Geothermal Sci. Tech., v.2 (3), pp.189228.

Bodvarsson, G.S., Pruess, K., Haukwa, C. and Ojiambo, S.B. (1990a) Evaluation of reservoir model predictions for Olkaria East geothermal field, Kenya. Geothermics, v.19(5), pp.399414.

Bodvarsson, G.S., Buornsson, S., Gunnarsson, A., Gunnlaugsson, E., Sigurdsson, O., Stefansson, V. and Steingrimsson, B. (1991) The Nesjavellir geothermal field, Iceland: 2. Evaluation of the generatingcapacity of the system. Journal of Geothermal Science and Technology, v.2 (4), pp.229-261.

Bower, K.M. and Zyvoloski, G. (1997) A numerical model for thermo-hydro-mechanical coupling in fractured rock. Internat. Jour. Rock Mechanics and Mining Sci., v.34 (8), pp. 12011211.

Brooks, R.H. and Corey A.T. (1964) Hydraulic Properties of Porous Media, Hydrolo. Pap.3. Civil Engineering Department. Colorado State University. Fort Collins.

Brown, D., DuTeaux, R., Kruger, P., Swenson, D. and Yamaguchi, T. (1999) Fluid circulation and heat extraction from engineered geothermal reservoirs. Geothermics, v.28, pp.553-572.

Brownell, D.H., S.K.Garg and Pritchett, W. (1977) Governing equations of geothermal reservoirs, Water Resour. Res., v.13(6), pp.929-935.

Burnell, J.G. (1992) Modeling mass, energy and chloride flows in the Rotorua geothermal system. Geothermics, v.21 (1/2), pp.261-280.

Butler, S.J., Sanyal, S.K., Henneberger, R.C., Klein, C.W., Gutierrez, P., and DE LeON V., J.S.(2000) Numerical modeling of the Cerro Prieto geothermal field, Mexico. Proceedings World Geothermal Congress, Kyushu-Tohuku, Japan, May 28 June 10, 2000, pp.2545-2550.

CADY, C.V. (1969) Model studies of geothermal fluid production. $\mathrm{PhD}$ thesis, Stanford University, Stanford, California.

Chandrasekharam, D. (2000) Geothermal Energy Resources of India, IBC Conference “Geothermal Power Asia 2000” Manila, Philippines.

Cheng, P. and LaU, K.H. (1973) Numerical modeling of Hawaiian geothermal resources. Geothermics, v.2, pp.90 93.

Dershowitz, W., Eiben, T., Follin, S. and Andersson, A. (1999) Alternative models project, Discrete fracture network modelling for performance assessment of Aberg. SKB R-9943, Svensk K. AB.

Dickson, M.H. and Fanelli, M. (2004) What is Geothermal Energy? Istituto di Geoscienze e Georisorse, CNR, Pisa, Italy,

Finsterle, S. and Pruess, K. (1999) Automatic calibration of geothermal reservoir models through parallel computing on a workstation cluster. Proceedings of the 24th Workshop on Geothermal Reservoir Engineering, Stanford University, Stanford, California, 25-27 January 1999, pp.123-130.

Finsterle, S., Pruess, K., Bullivant, D.P. and O’Sullivan, M.J. (1997) Application of inverse modeling to geothermal reservoir simulation. Proceedings of the 22nd Workshop on Geothermal Reservoir Engineering, Stanford University, Stanford, California, 27-29 January 1997, pp.309-316.

Gerke, H.H. and van Genuchten, M.Th. (1993) A dual-porosity model for simulating the preferential movement of water and solutes in structured porous media. Water. Resour. Res., v.29, pp.305-319.

Gerke, H.H. and van Genuchten, M.Th. (1993b) Evaluation of a first order water transfer term for variably saturated dualporosity ?ow models. Water Resour. Res., v.29, pp.12251238.

Ghassemi, A., Nygren, A. and Cheng, A. (2008) Effects of heat extraction on fracture aperture: A poro-thermoelastic analysis. Geothermics, v.37, pp.525-539.

Ghassemi, A. and Suresh Kumar, G. (2007) Changes in fracture aperture and fluid pressure due to thermal stress and silics dissolution/precipitation induced by heat extraction from subsurface rocks. Geothermics, v.36, pp.115-140.

Grant, M.A. (1983) Geothermal reservoir modeling. Geothermics, v.12, No.4, pp.251-263.

Gylling B., N., Marsic, K., Konsult AB, L., H. and D., H. (2004) Applications of hydrogeological modelling methodology using NAMMU and CONNECTFLOW. SKB R-04-45, Svensk K. $\mathrm{AB}$.

Hadgu, T., Zimmerman, R.W. and Bodvarsson, G.S. (1995) Coupled reservoir-wellbore simulation of geothermal reservoir behavior. Geothermics, v.24(2), pp.145-166.

Hanano, M. (1992a) Reservoir engineering studies of the 
Matsukawa geothermal field, Japan. Trans. Geothermal Resources Council, v.16, pp.643-650.

Hanano, M. (1992b) Simulation study of the Matsukawa geothermal reservoir: natural state and its response to exploitation. Jour. Energy Resources Tech., v.114, pp.309-314.

Hanano, M. and Seth, M.S. (1995) Numerical modeling of hydrothermal convection systems includingsuper-critical fluid. Proceedings World Geothermal Congress '95, Florence, 1831 May 1995, pp.1681-1686.

HaYBa, D.O. and IngEBritsen, S.E. (1997) Multiphase groundwater flow near cooling plutons. Jour. Geophys. Res., v.102 (B6), pp.12235-12252.

Hochstein, M.P. (1990) Classification and assessment of geothermal resources. In: M.H. Dickson and M. Fanelli (Eds.), Small geothermal resources, UNITAEWNDP Centre for Small Energy Resources, Rome, Italy, pp.31-59.

Hu, B. (1995) Reservoir simulation of the Yangbajian geothermal field in Tibet, China. Proceedings World Geothermal Congress '95, Florence, 18-31 May 1995, pp.1691-1695.

Indraratna, B., Ranjith, P.G., Price, J.R. and Gale, W. (2003) Two-phase (air and water) flow through rock joints: analytical and experimental studies. Jour. Geotech. Geoenviron. Engg., v.129(10), pp.918-925.

IngEBritsen, S.E. and Sorey, M.L. (1985) Quantitative analysis of the Lassen hydrothermal system, northcentral California. Water Resources Res., v.21(6), pp.853-868.

KIRYUKHIN, A.V. (1996) Modeling studies: the Dachny geothermal reservoir, Kamchatka, Russia. Geothermics, v.25(1), pp.6390.

KissLing, W.M. (1995) Extending MULKOM to super-critical temperatures and pressures. Proceedings World Geothermal Congress '95, Florence, 18-31 May 1995, pp.1687-1690.

Kocabas, I. (2005) Geothermal reservoir characterization via thermal injection backflow and interwell tracer testing. Geothermics, v.34. pp.27-46.

Kohl, T., Evans, K.F., Hopkirk, R.J. and Rybach, L. (1995a) Coupled hydraulic and mechanical considerations for the simulation of hot dry rock reservoirs. Geothermics, v.24 (3), pp.333-343.

MARTin, J.C. (1975) Analysis of internal steam drive in geothermal reservoirs. Paper SPE 5382 presented at the 45th Annual California Regional Meeting of the Society of Petroleum Engineers, AIME, Ventura, California.

Menzies, A.J. and Pham, M. (1995) A field-wide numerical simulation model of The Geysers geothermal field,California, USA. Proc. World Geothermal Congress '95, Florence, 1831 May 1995, pp.1697-1702.

Mercer Jr., J.W. and Pinder, G.F. (1973) Galerkin finite-element simulation of a geothermal reservoir. Geothermics, v.2, pp.8189.

Mercer,J.W., C.R Faust and Pinder, G.F. (1974) Geothermal reservoir simulation, Proceedings of the Conference on Reserch for the Development of Geothermal Energy Resources, Rep.RA-N-74-159. Nat. Sci. Found., Pasadena, Calif., Sept. 23-25.
Mercer, J.W. and Faust, C.R. (1979) Geothermal reservoir simulation.1.Mathematical models for liquid and vapordominated hydrothermal systems. Water Resour. Res., v.15(3), pp.653-671.

Mercer, J.W. and Faust, C.R. (1979). A review of numerical simulation of hydrological systems. Hydrological SciencesBulletin-des Sciences Hydrologiques, v.24, 3,9.

Mercer, J.W. and Faust, C.R. (1979) Geothermal reservoir simulation. 2. Numerical solution techniques for liquid and vapor-dominated systems. Water Resour. Res., v.15(3), pp.653671.

Mercer, J.W. and Faust, C.R. (1979) Geothermal reservoir simulation. 3. Application of liquid and vapor-dominated modelling techniques to Wairakei, New Zealand. Water Resour. Res., v.15(3), pp.653- 671.

Moridis, G. and Pruess, K. (1998) T2SOLV: An enhanced package of solvers for the TOUGH2 family of reservoir simulation codes. Geothermics, v.27(4), pp.415-444.

MuralidHar, K. (1990) Flow and transport in single rock fractures. Jour. Fluid. Mech. v.215, pp.481-502.

Murray, L. and GunN, C. (1993) Toward integrating geothermal reservoir and wellbore simulation: TETRAD and WELLSIM. Proceedings of the 15th New Zealand Geothermal Workshop, Auckland, New Zealand, 10-12 November 1993, pp.279284.

Noorishad, J. and Tsang, C.-F. (1996) ROCMAS simulator: a thermohydromechanical computer code. Stephansson, Jing and Tsang (eds.), Coupled Thermo-hydro-mechanical Processes of Fractured Media, Elsevier, Amsterdam, pp.551-558.

Natarajan, N. and Suresh Kumar, G. (2010) Effect of non linear sorption on solute transport in a coupled sinusoidal fracturematrix system. Internat. Jour. Environ. Sci., v.1(3), pp.323333.

O'Sullivan, M.J. (1985) Geothermal reservoir simulation. Energy Res., v.9, pp.313-332.

O'Sullivan, M.J., Barnett, B.G. and Razali, M.Y. (1990) Numerical simulation of the Kamojang geothermal field, Indonesia. Trans. Geothermal Resources Council, v.14, pp.1317-1324.

O'Sullivan, M.J., Bullivant, D.P., Follows, S.E., and Mannington, W.I. (1998) Modeling of the Wairakei -Tauhara geothermal system. Proceedings of the TOUGH Workshop ' 98 , Berkeley, California, 4-6 May 1998, pp.1-6.

O'Sullivan, M.J., Bodvarsson, G.S., Pruess, K., and Blakeley, M.R. (1985) Fluid and heat flow in gas-rich geothermal reservoirs. Soc. Petroleum Engg. Jour., v.25(2), pp.215-226.

O'Sullivan, M.J., Pruess, K. and LipPMann, M.J. (2001) State of the Art of Geothermal Reservoir Simulation, Geothermics, v.30 , pp.395-429,

PAlliser, C. and McKibiIn, R. (1998) A model for deep geothermal brines. I: T-p-X state-space description. Transport in Porous Media, v.33 (1/2), pp.65-80.

Pham, M. and Menzies, A.J.(1993) Results from a field-wide numerical model of The Geysers geothermal field. Trans. Geothermal Resources Council, v.17, pp.259-265. 
PhILLIP, J.R. (1968) The theory of absorption in aggregated media. Aust. Jour. Soil Res. v.6, pp.1-19.

Pritchett, J.W. and GarG, S.K. (1995) A modeling study of the Oguni geothermal field, Kyushu, Japan. Proc. World Geothermal Congress '95, Florence, 18-31 May 1995, pp.1727-1733.

Pritchett, J.W. (1995) STAR: A geothermal reservoir simulation system. Proc. World Geothermal Congress '95, Florence, 1831 May 1995, pp.2959-2963.

Pritchett, J.W., Rice, M.H. and Riney, T.D. (1981) Equation-ofstate for Water-Carbon Dioxide Mixtures: Implications for Baca Reservoir. Report DOE/ET/27163-8, Systems, Science and Software, La Jolla, CA.

Pruess, K. (2008) Numerical modeling of water injection into vapor-dominated geothermal reservoirs. Lawrence Berkeley National Laboratory. eScholarship. University of California.

Pruess, K. (1992) Brief guide to the MINC-method for modeling flow and transport in fractured media. Earth science division. Lawrence Berkeley Laboratory, University of California, Berkeley.

Pruess, K. (2002) Mathematical Modeling of Fluid Flow and Heat Transfer in Geothermal Systems-an introduction in five lectures. Geothermal training programme, IS-108, Reykjavik, Iceland.

Pruess, K. (1990b) TOUGH2- A General Purpose Numerical Simulator for Multiphase Fluid and Heat flow. Report: LBL29400, Lawrence Berkeley Laboratory, Berkeley, California.

Razdan, P.N., Agarwal, R.K. and Singh, R. (2008) Geothermal energy resources and its potential in India. e-Journal Earth Science India, v.1(1), pp.30-42.

Richards, H., Parker, R., Green, A., Jones, R., Nicholls, J., Nicol, D., Randall, M., Richars, S., Stewart, R. and WillisRichards, J. (1994) The performance and characteristics of the experimental Hot Dry Rock geothermal reservoir at Rosemanowes, Cornwall (1985-1988). Geothermics, v.23, pp.73-109.

Sakagawa, Y., Takahashi, M., Hanano, M., Ishido, T., and Demboya, N. (1994) Numerical simulation of theMori geothermal field, Japan. Proceedings of the 19th Workshop on Geothermal Reservoir Engineering, Stanford University, Stanford, California, 18-20 January 1994, pp.171-178.

Sanyal, S.K., Antunez, E.U., Abe, M. and NaKanishi, S. (1990) Numerical modeling of a mature high temperaturegeothermal reservoir: a case history from the Onikobe field, Miyagi prefecture, Japan. Transactions Geothermal Resources Council, v.14, pp.1339-1345.

Sanyal, S.K., Pham, M., Iwata, S., Suzuki, M., Inoue, T., Yamada, K. and Futagoishi, M. (2000 b) Numerical simulation of the Wasabizawa geothermal field, Akita Prefecture, Japan. Proc. World Geothermal Congress, Kyushu-Tohuku, Japan, May 28 June 10, 2000, pp.2189-2194.

Sarak, H., Onur, M. and Satman, A. (2003) Applications of lumped parameter models for low temperature geothermal reservoirs. Proc. 28th Workshop on Geothermal Reservoir Engineering,Stanford University, Stanford, California, January
27-29, 2003 SGP-TR-173.

Selroos, J.O., Walker, D.D., Ström, A., Gylling, B. and Follin, S. (2002) Comparison of alternative modelling approaches for groundwater flow in fractured rock. Jour. Hydrology, v.257(1-4), pp.174-188.

Simuonek, J., Wendroth, O., Wypler, N. and van Genuchten, M.Th. (2001) Nonequilibrium water ?ow characterized from an upward in?1tration experiment. Eur. Jour. Soil Sci., v.52 (1), pp.13-24.

Stopa, J. and Wojnarowski, P. (2006) Analytical model of cold water movement in a geothermal reservoir. Geothermics, v.35, pp.59-69.

Suresh Kumar, G. and Ghassemi, A. (2005). Numerical modeling of non-isothermal quartz dissolution/precipitation in a coupled fracture-matrix system. Geothermics, v. 34, pp.411-439.

Tenma, N., IkaWA, T. and Nagai. M. (1997) Productivity of a recent three-well system at Hijiori HDR test site. Proc $22^{\text {nd }}$ workshop on geothermal reservoir engineering. Stanford Univeristy. Stanford, CA., Jan. 27-29,1997, SGR-TR-155, pp. 191194.

Todesco, M. (1995) Modeling of the geothermal activity at Vulcano (Aeolian Islands, Italy). Proceedings World Geothermal Congress '95, Florence, 18-31 May, 1995, pp.1309-1314.

TUREYEn,O.I, ONUR, M. and SARAK H. (2009) A generalized nonisothermal lumped parameter model for liquid dominated geothermal reservoir. Proc. 34th Workshop on Geothermal Reservoir Engineering Stanford University, Stanford, California, February 9-11, 2009, SGP-TR-187.

van Genutchen, M.T.H. (1980) A closed form equation for predicting the hydraulic conductivity in soils. Soil. Sci. Am. Jour., v.44, pp.892-898.

Vinsome, P.K.W. and Shook, G.M. (1993) Multi-purpose simulation. Jour. Petroleum Sci.Engg. ,v.9 (1), pp.29-38.

Warren, J.E. and Root, P.J. (1963) The behavior of naturally fractured reservoirs. Soc. Petroleum Engg. Jour. September, Trans., AIME, v.228, pp.245-255,

White, S.P., Kissling, W.M. and McGuinness, M.J. (1997) Models of the Kawerau geothermal reservoir. Trans. Geothermal Resources Council, v.21, pp.33-40.

White,D.E., Muffler, L.P.J. and Truesdell, A.H. (1971) Vapordominated hydrothermal systems compared with hot water systems. Econ. Geol. v.66, pp.75-97.

Whiting, R.L. and RAmEY, H.J. Jr. (1969) Application of material and energy balances to geothermal steam production. Jour. Petrol. Tech., v.21(7), pp.893-900.

Williamson, K.H. (1990) Reservoir simulation of The Geysers geothermal field. Proceedings of the 15thWorkshop on Geothermal Reservoir Engineering, Stanford University, Stanford, California, 23-25 January 1990, pp.113-123.

Williamson, K.H. (1992) Development of a reservoir model of The Geysers geothermal field. Monograph on the Geysers Geothermal Field. Geothermal Resources Council, Special Report v.17, pp.179-187.

Witherspoon, P.A., Neuman, S.P., Sorey, M.L. and Lippman, M.J. (1975) Modeling of geothermal systems, paper presented at 
International meeting on geothermal phenomena and its application, Accad. Nat.dei Lincei, Rome, Italy, March 3-5.

Wu, Y.S. and Pruess, K. (2000) Integral solutions for transient fluid flow through a porous medium with pressure dependent permeability. Internat. Jour. Rock Mechanics and Mining Sci., v.37, pp.51-60.
YANO, Y. and IsHIDO, T. (1998) A reservoir engineering study on production behavior of deep-seated geothermal reservoirs. Trans. Geothermal Resources Council, v.22, pp.503-506.

Zyvoloski, G.A. and O’Sullivan, M.J. (1980) Simulation of a gasdominated two-phase geothermal reservoir.Society of Petroleum Engineers Journal. v.20, pp.52-58.

\title{
Announcement
}

\section{Geological Society of India}

\author{
Annual General Meeting - 2012
}

\section{and \\ National Seminar on "Mining and Community Welfare"}

At the invitation of the Society of Geoscientists and Allied Technologists (SGAT), the Annual General Meeting (AGM) of the Geological Society of India for 2012 will be held on 23rd September 2012 at Bhubaneswar, Odisha. A National Seminar organized by SGAT on "Mining and Community Welfare" will be held during $22^{\text {nd }}$ to $23^{\text {rd }}$ September, 2012 at Bhubaneswar. The Seminar will cover the following focal broad aspects:

- Legislative Provisions

- Areas of concerns

- CSR and beyond

- Role of Mining Industry, Governments and other Stakeholders

- Cased studies and Action plan

Scientists interested in participating in the National Seminar may please contact: Shri B.K. Mohanty, D-20, BJB Nagar, Bhubaneswar-751014, Odisha. Phone: +91-674-2431909, Mobile: +9437355664, Email: bkmohanty@mail.com or Shri R.H. Sawkar, Secretary, Geological Society of India, No.63, 12 ${ }^{\text {th }}$ Cross, Basappa Layout, Gavipuram P.O., P.B.No. 1922, Bangalore - 560 019; Telefax: 080-2661 3352, Phone: 080-2242 2943; Email: gsocind@gmail.com; Website: www.geosocindia.org. 